AperTO - Archivio Istituzionale Open Access dell'Università di Torino

\title{
Labile Sex Expression and the Evolution of Dioecy in Ophryotrocha Polychaete Worms
}

\section{This is a pre print version of the following article:}

Original Citation:

\section{Availability:}

This version is available http://hdl.handle.net/2318/150315

since 2016-06-23T10:54:48Z

Published version:

DOI:10.1007/s11692-014-9297-0

Terms of use:

Open Access

Anyone can freely access the full text of works made available as "Open Access". Works made available under a Creative Commons license can be used according to the terms and conditions of said license. Use of all other works requires consent of the right holder (author or publisher) if not exempted from copyright protection by the applicable law. 


\section{(3) \\ UNIVERSITÀ DEGLI STUDI DI TORINO}

This is an author version of the contribution published on: Questa è la versione dell'autore dell'opera: [Evolutionary Biology DOI: 10.1007/s11692-0149297-0]

7 The definitive version is available at: La versione definitiva è disponibile alla URL: 

polychaete worms

14

15

16

17

18

19

20

21

22

23

24

25

26

27

28

29

30

31 Short title: Labile sex expression in Ophryotrocha worms

32

33

34 4511; e-mail: stefania.meconcelli@unito.it
S. Meconcelli ${ }^{\S}$ M. C. Lorenzi ${ }^{\S}$, G. Sella ${ }^{\S}$

$\S^{\S}$ Department of Life Sciences and Systems Biology, Università di Torino, Turin, Italy.

correspondence: Stefania Meconcelli, Department of Life Sciences and Systems Biology, Università di Torino, Via Accademia Albertina 13, 10123 Turin, Italy. Tel.: +39 011670 
Abstract

Labile sex expression is considered to play a key role in the evolution of breeding systems and in the transition from hermaphroditism to dioecy, according to the evolutionary models proposed for plants. While in hermaphrodites sex allocation within the individual can be plastically adjusted in response to social environment, in dioecious species it is predicted to be fixed. However, labile sex expression in the form of gender plasticity can still be present in dioecious species of animals with environmental sex determination. It is still unclear how gender plasticity is involved in the evolution of breeding systems and what its role is in the transition from hermaphroditism to dioecy. We assessed the degree of plasticity in gender expression in three dioecious species of polychaete worms of the genus Ophryotrocha. We found sexual polymorphism and plasticity in sex expression during the juvenile phase to be a response to social environment. The majority of juveniles reared with an adult female or male expressed the gender opposite of that of the partner, so as to form heterosexual pairs. On the basis of these findings we outline a possible evolutionary pathway of the transition from hermaphroditism to dioecy in the genus Ophryotrocha. (1)

\section{Keywords:}

Gender plasticity; pseudohermaphrodite; monoecy; evolutionary transition; environmental sex determination

3

\section{4} 5 6 7

\section{Introduction}

9

Labile sex expression is widespread among plants and animals (Charnov and Bull 1977; Korpelainen 1990,1998; Delph and Wolf 2005). Natural selection is expected to favor organisms with labile sex expression when individual fitness as a male or female is strongly influenced by environmental factors and when parents cannot predict in which environment the offspring will live (Charnov and Bull 1977). 

more prone to adapt to different environments plastically (Bazzaz 1991). Indeed plants are often characterized by labile sex expression in response to different environmental conditions (Freeman et al. 1980). As a consequence of this high lability in sex expression, there is a large variety of breeding systems in plants in addition to dioecy and hermaphroditism - namely, gynodioecy, androdioecy and subdioecy (or trioecy) (Renner and Ricklefs 1995; Ehlers and Bataillon 2007). These latter breeding systems are considered to represent intermediate stages in the evolutionary transition between hermaphroditism and dioecy (Charlesworth and Charlesworth 1978; Freeman 1997; Delph 2005; Barrett 2013). For this reason, labile sex expression is considered to have an important role in the evolution of breeding systems and in the transition from hermaphroditism to dioecy (Freeman 1997; Delph and Wolf 2005; Crossman and Charlesworth 2013).

In animals, labile sex expression in the form of plasticity in gender expression is generally observed when the mechanism of sex determination is environmental (Charnov and Bull 1977; Mankiewicz et al. 2013). Environmental sex determination involving phenotypic plasticity in gender is common in invertebrates (Leonard 2013), while in vertebrates it has been found only in fishes and reptiles (Bull 1983; Godwin et al. 2003; Sarre et al. 2004). The environmental factors which influence sex expression in invertebrates, fish and reptiles are both abiotic (e.g., temperature, photoperiod, nutrition, density, pH, UV light, metabolic products, salinity and light) and biotic (e.g., parasites, exposure to the opposite sex, social cues and host characteristics in parasitoids) (Bull 1983; Korpelainen 1990; Godwin et al. 2003; Sarre et al. 2004).

Adaptation of sex expression to the environment is also a common feature of hermaphroditic plants and animals (Charnov 1977). Both are able to allocate reproductive resources to female and male function in response to environmental conditions, such as population size or mating opportunities (Pannell 1997; Charnov 1977; Korpeleinen 1998; Schärer 2009; Schleicherová et al. 2014).

Sex allocation theory mainly focuses on species with fixed sex expression, while several species display labile sex expression. According to sex allocation theory, dioecious species are only able to change their offspring sex ratio (Charnov 1982; Schärer 2009). Therefore, within the individual, the expression of gender and sex allocation are predicted to be fixed, independent of group size variations and uninfluenced by mating opportunities.

In contrast with this prediction, plasticity in gender expression can still be present in dioecious species that have a hermaphroditic ancestor and environmental sex determination, at least in the developmental stage (Korpelainen 1998). Little is known about the degree of plasticity in gender expression in dioecious species of 
animals with environmental sex determination. In some of these species, plasticity in gender expression during the juvenile phase can be elicited by the gender of a conspecific adult. If that adult represents the only social environment that the juvenile will experience, as in a low density population, we can expect that the juvenile will be able to express the gender opposite to that of the adult. There are several examples among invertebrates of this kind of influence on gender expression: the marine worm Bonellia viridis (Echiura) (Bacci 1965; Leutert 1975; Agius 1979; Berec 2005), the siboglinid worms of the genus Osedax (Vrijenhoek et al. 2008), the crustacean parasites Pachypygus gibber (Copepoda) (Hipeau-Jacquotte 1978; Becheikh et al. 1998; Michaud et al. 2004), Ione thoracica (Isopoda) and Stegophryxus hyptius (Isopoda), some parasitic species of mermithids (Nematoda) (Parenti 1965) and the dioecious species of the marine polychaete worms of the genus Ophryotrocha (Rolando 1984).

In the genus Ophryotrocha there are dioecious, simultaneously hermaphroditic and sequentially hermaphroditic species and all of them show a large extent of labile sex expression in response to social conditions. Therefore this genus presents us with a target model system for studying the plasticity of gender expression from an evolutionary perspective. For example, in the sequential hermaphroditic species $O$. puerilis, when pairs of two females are formed, one of the two worms, usually the youngest one, changes to the male sex, so as to form a heterosexual pair (Åkesson 1974; Pfannenstiel 1975, 1977; Kegel and Pfannenstiel 1983; Berglund 1986). In the dioecious species Ophryotrocha labronica and other Ophryotrocha dioecious species, sex expression in a juvenile is influenced by the presence of a sexually mature worm so that the juvenile will develop the sex opposite to that of its partner significantly more often than expected (Bacci et al. 1979; Rolando 1983, 1984). Conversely, abiotic environmental factors have no influence on gender expression (Åkesson 1975; Prevedelli et al. 1998; Prevedelli and Simonini 2001). Moreover, some Ophryotrocha dioecious species cannot be defined as purely dioecious. The presence of four sexual phenotypes (i.e. pure male, male with a few oocytes, pure female, and female with a few sperm) has been reported repeatedly (Pfannenstiel 1976; Rolando and Giorda 1982; Rolando 1983; Lorenzi and Sella 2013). Lorenzi and Sella (2013) interpret this sexual polymorphism as a vestigial trait of an ancestral hermaphroditic state, which was inferred from phylogenetic analyses based on morphological and molecular markers (Dahlgren et al. 2011; Thornhill et al. 2009).

As opposed to plants, in animals it is still unclear how gender plasticity is involved in the evolution of breeding systems and what its role is in the transition from hermaphroditism to dioecy. Therefore the study of the variation of plasticity in the expression of the sexual phenotypes may help to identify a possible evolutionary pathway of the evolution of dioecy 
123 from a hermaphroditic ancestor. If plastic sex allocation in response to social group size is one

124 of the main advantages of hermaphroditism over dioecy (Schärer 2009), we can expect a

125 reduction or a loss of plasticity in sex allocation in the transitions from hermaphroditism to

126 dioecy. This reduction of plasticity could be manifested as a decrease in the ability of sensing

127 and/or responding to environmental stimuli, or as a reduction of the time-window when

128 plasticity can be expressed. In the present study, we tested for variations in the degree of

129 gender plasticity of juveniles and adults in three sexually dioecious species of Ophryotrocha

130 worms - Ophryotrocha labronica, Ophryotrocha robusta and Ophryotrocha macrovifera,

131 according to the social environment they were exposed to - i.e the presence of an adult male

132 or female. The three species have similar morphology and reproductive biology but they

133 differ in some genomic aspects (O. macrovifera and O. labronica have a different number of

134 chromosomes compared to $O$. robusta (Robotti et al. 1991); and the genome size of $O$.

135 macrovifera is twice that of the other two species (Sella et al. 1993)). The three species

136 diverge also in their geographical distribution (Simonini 2009; Paxton and Åkesson 2010).

In the current study, ee found that plasticity in gender expression in the three species was confined to the juvenile stage, that four sexual phenotypes (pure males, pure females,

139 males with a few oocytes and females with a few sperm) were expressed in the populations of

140 the three species and that, in the adult phase, individuals expressed only one of the four sexual

141 phenotypes. The presence of sexual polymorphism among adults together with plasticity in

142 the sex expression of juveniles allowed us to outline the transition from ancestral

143 simultaneous hermaphroditism to dioecy via monoecy (i.e. a situation where the

144 hermaphroditic organism has distinct female and male gonads) as the most likely evolutionary

145 pathway (Freeman et al. 1997; Golenberg and West 2013). 


\section{Study species and animal rearing}

150 The external morphology and life cycle parameters of O. labronica, O. robusta and O. macrovifera are only

151 slightly different (Table 1). In the three species mating is achieved by pseudo-copulation, a process of external

152 fertilization in which partners reach close physical contact before releasing their gametes (Westheide 1984).

153 Eggs are released in water and are enveloped by a transparent mucous cocoon, through which egg development

154 can be easily observed. Females grow faster than males and reach sexual maturity at a body size larger than that

155 of males. Both sperm and oocytes originate from the same clusters of primordial germ cells and then mature

156 freely floating in the coelom (Pfannenstiel and Grünig 1982; Brubacher and Huebner 2009). Ripe oocytes can be

157 easily seen from the transparent body walls, while unripe oocytes and sperm can only be observed after intense

158 manipulations of worms. Sexual dimorphism consists of a wider prostomium and a larger and thicker upper jaw

159 in males than in females. These traits, together with presence of visible oocytes, make it easy to distinguish

160 males from females by visual inspection. In addition, males have more rosette glands than females. Rosette

161 glands are located dorsally one per segment on the posterior segments of the body. The rosette glands have been

162 described for all the three species (Paxton and Åkesson 2010), but their function has never been investigated.

163 They can be easily observed under a phase-contrast microscope (250X). Sexual dimorphism in secondary sexual

164 traits such as prostomium and jaw size and shape allowed us to distinguish only two sexual phenotypes, male

165 and female, although four sexual phenotypes (pure female, pure male, male with oocytes and female with sperm)

166 can be identified in these worms by also looking at the types of gametes present in every individual.

167 In Ophryotrocha species, the sex determining mechanism and sex ratio control are supposed to be polygenic

168 (Bacci 1978; Premoli et al. 1996). Polygenic systems are known to be very sensitive to various environmental

169 effects (Falconer 198; Bull 1983). However in Ophryotrocha species, abiotic environmental factors such as

170 temperature, photoperiod, salinity, artificial or natural marine water and diet do not influence gender expression

171 (Åkesson 1975; Prevedelli et al. 1998; Prevedelli and Simonini 2001).

172 Ophryotrocha species occur interstitially, at relatively low density in shallow, nutrient-rich waters

173 (Thornhill et al. 2009). Ophryotrocha labronica has a cosmopolitan worldwide distribution (Paxton and Åkesson

174 2010) and inhabits both harbors and brackish water environments (Simonini 2009). O. macrovifera is much rarer

175 than $O$. labronica. It was found in only a few localities along the Mediterranean sea and the North Atlantic 176 coasts (Paxton and Åkesson 2010; Simonini 2009). O. robusta is endemic to the Mediterranean sea, where it 177 occurs only in a few localities (Paxton \& Åkesson, 2010, Simonini, 2009). Because of the low mobility of these 
worms, different populations are supposed to be quite reproductively isolated (Lanfranco and Rolando 1981; Sella and Robotti 1986).

All experiments were carried out using laboratory populations established several years ago starting from large samples of worms collected from the wild (O. macrovifera from Chioggia, Italy (2006), O. labronica from Alamitos Beach, Long Beach, California, USA (2005) and O. robusta from Porto Empedocle, Italy (2010)). Animals were reared in $30 \mathrm{ml}$ bowls with filtered artificial marine water (33 psu) at a constant temperature of 21 ${ }^{\circ} \mathrm{C}$ and fed with spinach ad libitum.

\section{Experimental design}

To test how the presence of an adult male or female influences the expression of the sexual phenotype in juveniles in the three species, we set up 55 pairs of parents (20 pairs of $O$. labronica, 20 pairs of $O$. macrovifera and 15 pairs of $O$. robusta). From the offspring of these pairs we selected 330 juveniles (6 per pair) (hereafter "experimental worms") as soon as they had a body length of 3 segments with setae. The selected juveniles were assigned to three treatments (2 experimental worms of each family per treatment) (Figure 1): 1) juvenile paired with an adult female, 2) juvenile paired with an adult male, and 3) juvenile isolated as a control. We expected experimental worms to develop the gender opposite to that of their partner. Therefore, we expected sex ratio in treatment 1) and 2) to differ from the sex ratio in our control treatment. Adult males and females (hereafter "partners") used in treatments 1) and 2) were obtained from the progeny of 108 pairs (36 per species) and were all of the same age (21 days). When the experimental worms reached a clear sexual differentiation, we sexed them. They were sexed according to the presence of visible oocytes in females and of a prostomium and an upper jaw larger in males than in females.

To test the effect of the presence of an adult male or female on the expression of the sexual phenotypes of sexually mature individuals of the three species, we used a subsample of the sexually mature experimental worms and formed 87 homosexual pairs by pairing each of them with a partner. If gender plasticity is still present in the adult stage, we can expect 
205 worms in homosexual pairs to be stimulated to produce gametes of the sex opposite to that of

206 their partner's. Ninety heterosexual pairs were set up as controls. To check for the presence of oocytes in males and sperm in females, we needed to kill worms. Therefore we formed these pairs relying on external sexual dimorphism only, thus without distinguishing pure females

209 from females with sperm and pure males from males with oocytes. Pairs were reared for a

210 time interval that allowed all the heterosexual pairs to lay at least two egg masses. We 211 guessed that those homosexual pairs in which at least one of the partners had both oocytes and sperm would have had the opportunity to lay at least one egg mass in that same time interval.

All experimental worms were eventually checked for sperm in females or oocytes in males. To check for the presence of sperm, worms were gently squeezed between two slides, so that sperm oozed out of the parapodia, and were observed by phase-contrast microscopy (250X). Oocytes can be easily identified from the transparent body walls of the worms at 250X magnification. Females that had sperm and males that had oocytes were classified as pseudohermaphrodites, because generally in these worms only one type of gamete is functional (Baldi et al. 2009; Lorenzi and Sella 2013). In a subsample of worms ( $\mathrm{n}=184 ; 64$ from treatment 1, 57 from treatment 2 and 63 from treatment 3 ), we measured the developmental time to sexual differentiation as the number of days from the stage of 3 segments with setae to sexual maturity.

In order to check for a correlation between sexual phenotype and number of rosette glands (Lorenzi and Sella 2013; Paxton and Åkesson 2010), we also measured the number of rosette glands and the number of segments with setae (as an estimate of body size) in the same subsample. Measures were taken under phase-contrast microscopy (250X).

\section{Statistical analysis}

We first focused on sex ratio, i.e., the effect of social environment during the juvenile phase on worm sex 
231 binomial distribution. Sex was assigned based on external morphology, therefore juveniles became either males 232 (pure males and males with oocytes) or females (pure females and females with sperm). Predictor variables included species and social environment (i.e. juvenile + male, juvenile + female, isolated juvenile). The sibship

234 of every experimental worm was added as a random blocking to control for similarities in the proportion of the 235 different sexual phenotypes within families. Since the sex of worms was not significantly affected by treatment 236 during the adult phase, in the GLMM we used all the data obtained from the 330 juveniles that entered the 237 experiment.

238 Then, we focused on how many juveniles matured the gender opposite to their partner's. Using a Generalized 239 Linear Model (GLM) with Poisson error distribution and a log link function, we analyzed the difference between 240 the number of experimental worms that matured the gender opposite to their partner's and the number of 241 experimental worms that matured the same gender as their partner's (heterosexual pairs vs. homosexual pairs). In 242 this statistical analysis pseudohermaphrodites (males with oocytes and females with sperm) were therefore excluded. The same statistical analysis was used to compare the number of pseudohermaphrodites among the three social environments and species.

Using a Generalized Linear Mixed Model (GLMM) with Poisson error distribution and a log link function, we also analyzed the developmental time (i.e., the number of days that passed from the stage of 3 segments with setae to the sexual differentiation stage). Predictor variables included sexual phenotype, species and social environment. The sibship of every experimental worm was handled as the random factor. Three different GLMMs, one for every sexual phenotype (males, females and pseudohermaphrodites), were made to compare the developmental times among the three social environments. As in the previous analysis, predictors were species and social environment, while sibship was a random factor. We used the results of these statistical tests only to assess differences in developmental times between social environments within the same sexual phenotype.

For all the analyses, we followed a model selection process based on Aikaike's information criterion

255 (AIC), which is a measure of model fit. AIC was recorded from models including all possible combinations and 256 interactions of effects, and we selected the model having the lowest AIC (Quinn and Keough 2002). In the GLMM and GLM with Poisson error distribution we also checked for overdispersion. 
261 distribution and a log link function. To analyze the number of rosette glands, we used the following factors as 262 explanatory variables: species, sexual phenotype, social environment and body size. Model selection and 263 statistical assumptions were checked, as described for the previous analysis.

\section{Results}

\section{Type and frequency of sexual phenotypes of the experimental worms}

In the three species, we found four sexual phenotypes, i.e. $39.3 \%$ pure males, $35.6 \%$ pure females, $19.1 \%$ females with sperm and $6.0 \%$ males with oocytes. The frequencies of males (pure males and male with oocytes) and females (pure females and females with sperm) were not significantly different among species and were significantly affected by the gender of the adult to which juveniles were exposed (Table 2 and Figure 2). The interaction between these two predictors was removed after checking it was non-significant in a preliminary analysis, which suggested that the social environment had the same impact on the juveniles of the three species. Statistical comparisons show that the difference in sex ratio among "social environments" is due mainly to the difference between the environment "juvenile+ female" and the other two social environments (Table 2), indicating female as the sex able to affect juvenile sexual development.

When juveniles reached sexual maturity, they formed true heterosexual pairs with their adult partner (pure male + pure female) $(47.5 \%)$ significantly more often than true homosexual pairs (pure male + pure male or pure female + pure female) $(31.1 \%)\left(G L M\right.$ with Poisson error distribution: d.f. $=2, \chi_{(\text {Wald })}^{2}=19.56, P<0.001$; heterosexual pairs (pure male + pure female) $v s$ homosexual pairs (pure male + pure male or pure female + pure female), $\left.B=0.42, \chi_{(\text {Wald })}^{2}=6.55, P=0.01\right)$. The remaining pairs $(21,4 \%)$ were composed of at least one male with oocytes or one female with sperm. In the subsequent analysis, we merged these two intermediate phenotypes together to form the experimental group of pseudohermaphrodites, since females with sperm and males with oocytes were relatively rare phenotypes. The number of pseudohermaphrodites depended significantly on species and social environment (Figure 3$)\left(\mathrm{GLM}\right.$ : species, $\chi_{(\text {Wald })}^{2}=25.74$, d. f. $=2, P<0.001$; social environment, $\chi_{(\text {Wald })}^{2}=25.74$, d. f. $=2, P<0.001$ ). The number of pseudohermaphrodites was significantly higher when juveniles developed in isolation than when they developed together with males $\left(B=0.75, \chi^{2}\right.$ (Wald) $=$ $25.69, P<0.0001)$ or with females $\left(B=0.27, \chi_{(\text {Wald })}^{2}=4.41, P=0.036\right)$. 


\section{Developmental time to sexual maturity}

The developmental time of juveniles was significantly different among species and sexual phenotypes, but juveniles of the three species adjusted their developmental time to social conditions in a similar way, although sexual phenotypes responded differently to social environment (Table 3). The developmental time of juveniles that expressed the same gender of their adult partner was significantly longer than that of juveniles which expressed the gender opposite to that of their partner (Table 3 and Figure 4). Overall, juveniles that developed in isolation had developmental times which were generally intermediate compared to the developmental times of their conspecifics exposed to adults. The large variations between species and phenotypes do not allow to identify clear, common effects of isolation on developmental times (Figure 4).

\section{Expression of the sexual phenotypes of sexually mature worms}

No differences were observed in the number of sexual phenotypes between worms in homosexual pairs and worms in heterosexual pairs during the adult phase $\left(\chi^{2}=0.43\right.$, d.f. $=3$, $P=0.93)$. Pairing off with a worm of the same sex did not stimulate the production of gametes of the opposite sex. In those homosexual pairs that were composed of two females, worms occasionally laid eggs. Egg laying occurred in 4 out of 16 homosexual pairs of females in O. robusta, in 2 out of 39 pairs in O. macrovifera and in 5 out of 32 pairs in O. labronica. Therefore in those homosexual pairs at least one of the partners was a female with sperm. We

310 do not know whether fertilized eggs were the result of a self-fertilization process or whether

311 the homosexual pairs were functionally heterosexual pairs.

\section{Rosette glands}

313 The number of rosette glands was positively associated to body size and varied significantly between species

314 and sexual phenotypes, but no interaction between the two factors was found (Figure 5). In all the three species

315 the number of rosette glands was larger in males than in females and pseudohermaphrodites (GLM: species, log- 
likelihood chi-square $\left(G^{2}\right)=19.87$, d. f. $=2, P<0.001$; sexual phenotype, $G^{2}=80.20$, d. f. $=2, P<0.0001$; social environment, $G^{2}=5.64$, d. f. $=2, P>0.05$; body size, $G^{2}=170.7$, d. f. $\left.=1, P<0.0001\right)$. The number of rosette glands was significantly different between males and females $\left(B=-0.39, \chi_{(\text {Wald })}^{2}=1.88, P<0.0001\right)$, males and pseudo-hermaphrodites $\left(B=-0.52, \chi_{(\text {(Wald })}^{2}=0.69, P<0.0001\right)$, while it was not different between females and pseudo-hermaphrodites $\left(B=-0.13, \chi_{(\text {Wald })}^{2}=2.64, P=0.10\right)$. This means that only two sexual phenotypes, male and female, can be distinguished according to the number of rosette glands.

\section{Discussion}

Our results showed that social environment - i.e. the presence of a sexually mature partner - influenced the expression of the sexual phenotype in juveniles of the Ophryotrocha dioecious species. The effect was documented 1) by variations of the frequencies of sexual phenotypes according to the social environment. Indeed juveniles tend to develop so as to form heterosexual pairs.. Furthermore the absence of a partner stimulated the production of pseudohermaphroditic sexual phenotypes. Indeed pseudohermaphrodites were significantly more common among isolated juveniles than among juveniles reared with adults of either sex. The effect of social environment was also documented 2) by the significantly different developmental times to the onset of sexual maturity of juveniles. Juveniles which have matured the same gender of their adult partner needed longer time to reach sexual maturity than juveniles which had matured the gender opposite to that of their partner's in all three species.

Sex expression was influenced by social conditions only during the juvenile phase for all the three species. This can be expected in species whose populations have largely fluctuating densities and live in patchy environments, such as intertidal communities do (Sella and Ramella 1999; Prevedelli et al. 2005). During the adult phase, frequencies of sexual phenotypes were no longer influenced by the social environment, as expected in species that 
underwent selective pressures for sexual specialization towards dioecy. Ophryotrocha dioecious species are therefore another example of labile gender maturation of juveniles in response to the presence of a sexual mature partner, in addition to those reported by Leutert (1975), Berec (2005); Bacci (1965), Agius (1979), Hipeau-Jacquotte (1978), Beckeickh et al. (1998), Michaud et al. (2004), Parenti (1965) and Vrijenhoek et al. (2008).

Although the three species differ from each other in their geographical distribution, genome structure and life cycle, they did not differ in their degree of plasticity in sexual expression at the end of the juvenile phase. Looking both at the propensity of juveniles to develop the gender opposite to that of their partner's and to vary in their developmental time according to their response to social conditions, the three species behaved in a similar way (as shown from the absence of statistical interactions involving species as a predictor variable). This interspecific homogeneity can be due either to the phylogenetic proximity (Dahlgren 2001) or to maintenance of plasticity in sex expression during development as an adaptive response to common selective forces.

Not all experimental worms reacted in the same way to the social environment: $31.12 \%$ of juveniles matured the same gender of their partner. Nevertheless, they showed a longer developmental time than that of juveniles which developed the gender opposite to that of their adult partner's. This result suggests that in Ophryotrocha worms the degree of sensing and/or responding to stimuli from adult partners is also influenced by genetic variations between individuals. In a similar way social environments influence juveniles sexual development differently: looking at the external morphology of experimental worms only adult females are able to influence the sex of juveniles (Figure 2). However when looking at gametes production we can asses also a influence of adult males on juveniles sexual development since the number of juveniles developed to pseudohermaphrodites is lower when juveniles are paired with males compare to isolated juveniles (Figure 3). According to these 
results, the most recent theories about phenotypic plasticity (West-Eberhard 2003; Ah-King and Nylin 2010; Golenberg and West 2013), identify two factors involved in determining the final sexual phenotype: 1) variations in the sequences of regulatory genes responsible for the control of alternative developmental pathways and 2) environmental stimuli.

The results of our experiment made it possible for us to outline a possible evolutionary pathway of the evolution of dioecy from a hermaphroditic ancestral state in Ophryotrocha. In plants, the transition from hermaphroditism to dioecy is thought to have evolved through two main distinct pathways (Ehlers and Bataillon 2007): from hermaphroditism via gynodioecy to dioecy and from hermaphroditism via monoecy to dioecy. Gynodioecy refers to the coexistence in a population of two sexual phenotypes, i.e. pure females and individuals having both sexual functions (within the same flower or in separate flowers), while monoecy refers to plants having both sexual functions in separate male and female flowers within the same individual (Ehlers and Bataillon 2007). In animals the distinction between individuals having both sexual functions either within the same flower or in separate flowers translates respectively to syngonic (the same gonads producing both male and female gametes) or digonic (distinct male and female gonads in the same individual) simultaneous hermaphrodites (Vega-Frutis et al. 2014).

The pathway through gynodioecy (Charlesworth and Charlesworth 1978; Delph and Wolf 2005) is based on two mutational events. Starting from a population of hermaphrodites, a first mutation is responsible for the production of pure females, so that the remaining hermaphrodites will be selected to plastically adjust their sex allocation and becoming strongly male biased. A second mutation will then generate pure males that will spread and outnumber the strongly male-biased hermaphrodites. This model relies on a genetic assumption (the first genetic mutation) and does not include gene $\mathrm{x}$ environment interactions (Freeman 1997). In species evolving through this pathway, gender expression should vary 
only in hermaphrodites as a consequence of the presence of pure females rather than other environmental conditions. Moreover, the model predicts that when pseudohermaphroditic phenotypes are present, they belong to the male gender, i. e. the gender which did not undergo the first genetic mutation determining male-sterility (Ehlers and Bataillon 2007).

In contrast, the pathway through monoecy (Renner and Ricklefs 1995) is based on mechanisms of regulation of gender expression triggered by variations in environmental cues. A mutation of the regulatory sequence of sex expression would determine the tendency to express one gender only, setting the evolutionary stage of dioecy or subdioecy. At this stage the sexual development of the organism is still directly dependent on the perception of external environmental cues and therefore it will maintain its ability to adapt to environmental variations plastically. Following this evolutionary model, during the transition, pseudohermaphroditic phenotypes should be common and extreme phenotypes (pure male and pure female) rare, since all individuals retain the ability to express both sexual phenotypes (Freeman 1997).

Our results fit well a possible monoecy pathway in which both the influence of social conditions on sex expression and the presence of pseudohermaphrodites can be explained. It is difficult to classify the pseudohermaphroditic phenotypes of dioecious species as syngonic or digonic, since only clusters of germ cells, and no true gonads, are present. They are hermaphroditic phenotypes with strong male- or female-biased sex allocation, and with rare gametes of the opposite sex. However, simultaneous hermaphroditic species of this genus also have spatially separate male and female sections (in the first 2-3 body segments these hermaphrodites produce only sperm, while in the remaining segments they produce only oocytes) (Åkesson 1974; Schleicherová et al. 2014). Therefore, they resemble digonic rather than syngonic simultaneous hermaphrodites. 
417 sexual specialization (Freeman 1997 and references therein). In animals, selective pressures

418 leading to sexual specialization are poorly known (but see Weeks 2012). In the populations of

419 the hermaphroditic ancestor of the dioecious Ophryotrocha species, selection for sexual

420 specialization would have been responsible for the appearance of pseudohermaphrodites (in

421 which both types of gametes are present but only one type is functional) and then of pure

422 males and pure females. One may wonder why pseudohermaphrodites still coexist with pure

423 males and pure females in the existing populations of Ophryotrocha. According to Ehlers and

424 Bataillon (2007) and Lorenzi and Sella (2013) selection for sexual specialization may become

425 less strong or ineffective when pseudohermaphrodites are strongly biased towards one of the

426 two genders. In the Ophryotrocha dioecious species, the dichotomy between sexual

427 dimorphism at the morphological level and sexual polymorphism at the gamete level is

428 illustrated well by the number of rosette glands. This sex-related trait allowed us to

429 distinguish only two reproductive morphs (males and females), while at the gamete level four

430 sexual phenotypes exist (pure male, pure female, male with oocytes and female with sperm).

431 If we can find out more precisely what the function of rosette glands is, we can more easily

432 understand what the selective pressures are that act for sexual specialization and hence drive

433 the evolution of dioecy in this genus.

\section{Acknowledgments}

We thank Liliana Ramella, Chiara Nebiolo and Alessandra Lerda for assistance in the

437 laboratory. We are grateful to Vincent Marsicano for help with linguistic revision. 


\section{References}

440

441

442

443

444

445

446

447

448

Agius, L. (1979). Larval settlement in the echiuran worm Bonellia viridis: settlement on both the adult proboscis and body trunk. Marine Biology, 53(2), 125-129.

Ah-King, M., \& Nylin, S. (2010). Sex in an evolutionary perspective: just another reaction norm. Evolutionary biology, 37(4), 234-246.

Åkesson, B. (1974). Reproduction and Larval Morphology of Five Ophryotrocha Species (Polychaeta, Dorvilleidae). Zoologica Scripta, 2(4), 145-155.

Åkesson, B. (1975). Reproduction in the genus Ophyotrocha (Polychaeta, Dorvilleidae).[Conference paper]. Pubblicazioni della Stazione Zoologica, Napoli.

Bacci, G. (1965). Sex determination. Pergamon Press, Oxford.

Bacci, G. (1978). Genetics of sex determination in Ophryotrocha (Annelida, Polychaeta). Marine organisms: genetics, ecology, and evolution. Plenum Press, New York.

Bacci, G., Lanfranco, M., Mantello, I., \& Tomba, M. (1979). A new pattern of hermaphroditism (inducible hermaphroditism) in populations ofOphryotrocha labronica (Annelida Polychaeta). Experientia, 35(5), 605-606.

Baldi, C., Cho, S., \& Ellis, R. E. (2009). Mutations in two independent pathways are sufficient to create hermaphroditic nematodes. Science, 326(5955), 1002-1005.

Barrett, S. C. (2013). The evolution of plant reproductive systems: how often are transitions irreversible? Proceedings of the Royal Society B: Biological Sciences, 280(1765), 20130913.

Bazzaz, F. (1991). Habitat selection in plants. American Naturalist, 137(supplement: hab). 
Becheikh, S., Michaud, M., dé ric Thomas, F., Raibaut, A., \& Renaud, F. (1998). Roles of resource and partner availability in sex determination in a parasitic copepod. Proceedings of the Royal Society of London. Series B: Biological Sciences, 265(1402), 1153-1156.

Berglund, A. (1986). Sex change by a polychaete: effects of social and reproductive costs. Ecology, 67(4), 836-845.

Brubacher, J. L., \& Huebner, E. (2009). Development of polarized female germline cysts in the polychaete, Ophryotrocha labronica. Journal of morphology, 270(4), 413-429.

Bull, J. J. (1983). Evolution of sex determining mechanisms: The Benjamin/Cummings Publishing Company, Inc.

Charlesworth, B., \& Charlesworth, D. (1978). A model for the evolution of dioecy and gynodioecy. American naturalist, 975-997.

Charnov, E. L., \& Bull, J. (1977). When is sex environmentally determined?

Crossman, A., \& Charlesworth, D. (2013). Breakdown of dioecy: models where males acquire cosexual functions. Evolution.

Dahlgren, T. G., Åkesson, B., Schander, C., Halanych, K. M., \& Sundberg, P. (2001). Molecular phylogeny of the model annelid Ophryotrocha. The Biological Bulletin, 201(2), 193-203.

Delph, L. F., \& Wolf, D. E. (2005). Evolutionary consequences of gender plasticity in genetically dimorphic breeding systems. New Phytologist, 166(1), 119-128.

Ehlers, B. K., \& Bataillon, T. (2007). 'Inconstant males' and the maintenance of labile sex expression in subdioecious plants. New Phytologist, 174(1), 194-211. 
Falconer, D. (1981). Introduction to Quantitative GeneticsLongman Inc. New York, NY.

Freeman, D., Harper, K., \& Charnov, E. (1980). Sex change in plants: old and new observations and new hypotheses. Oecologia, 47(2), 222-232.

Freeman, D. C., Doust, J. L., El-Keblawy, A., Miglia, K. J., \& McArthur, E. D. (1997). Sexual specialization and inbreeding avoidance in the evolution of dioecy. The Botanical Review, 63(1), 65-92.

Godwin, J., Luckenbach, J. A., \& Borski, R. J. (2003). Ecology meets endocrinology: environmental sex determination in fishes. Evolution \& development, 5(1), 40-49.

Golenberg, E. M., \& West, N. W. (2013). Hormonal interactions and gene regulation can link monoecy and environmental plasticity to the evolution of dioecy in plants. American journal of botany, 100(6), 1022-1037.

Hipeau-Jacquotte, R. (1978). Existence de deux formes sexuelles mâles chez le copépode ascidicole Notodelphyidae Pachypygus gibber (Thorell, 1859). Comptes Rendus de I'Academie des Sciences, Paris, 287 D, 253-256.

Kegel, B., \& Pfannenstiel, H.-D. (1983). Evaluation of the pair-culture effect inOphryotrocha puerilis (Polychaeta: Dorvilleidae). I. Pair-culture effect and sex ratio. Helgoländer Meeresuntersuchungen, 36(2), 205-213.

Korpelainen, H. (1990). Sex ratios and conditions required for environmental sex determination in animals. Biological Reviews, 65(2), 147-184.

Korpelainen, H. (1998). Labile sex expression in plants. Biological Reviews, 73(2), 157-180.

La Greca, M., \& Bacci, G. (1962). Una nuova specie di Ophryotrocha delle coste tirreniche (Annelida, Polychaeta). Italian Journal of Zoology, 29(1), 7-18. 
Lanfranco, M., \& Rolando, A. (1981). Sexual races and reproductive isolation in Ophryotrocha labronica La Greca and Bacci (Annelida, Polychaeta). Italian Journal of Zoology, 48(3-4), 291-294.

Leonard, J. L. (2013). Williams' Paradox and the role of phenotypic plasticity in sexual systems. Integrative and comparative biology, 53(4), 671-688.

Leutert, R. (1975). Sex-determination in Bonellia. In Intersexuality in the animal kingdom (pp. 84-90): Springer.

Lorenzi, M. C., \& Sella, G. (2013). In between breeding systems: neither dioecy nor androdioecy explains sexual polymorphism in functionally dioecious worms. Integrative and comparative biology, 53(4), 689-700.

Mankiewicz, J. L., Godwin, J., Holler, B. L., Turner, P. M., Murashige, R., Shamey, R., et al. (2013). Masculinizing effect of background color and cortisol in a flatfish with environmental sex-determination. Integrative and comparative biology, 53(4), 755765.

Michaud, M., de Meeûs, T., \& Renaud, F. (2004). Environmental sex determination in a parasitic copepod: checking heterogeneity and unpredictability of the environment. Marine Ecology Progress Series, 269, 163-171.

Pannell, J. (1997). Variation in sex ratios and sex allocation in androdioecious Mercurialis annua. Journal of Ecology, 85(1), 57-69.

Parenti, U. (1965). Male and female influence of adult individuals on undifferentiated larvae of the parasitic nematode Paramermis contorta. Nature, 207, 1105-1106. 
525 Paxton, H., \& Åkesson, B. (2010). The Ophryotrocha labronica group (Annelida, Dorvilleidae)—with the description of seven new species. Zootaxa, 2713, 1-24.

Pfannenstiel, H.-D. (1975). Mutual influence on the sexual differentiation in the protandric polychaete Ophryotrocha puerilis. In Intersexuality in the animal kingdom (pp. 48-56): Springer.

Pfannestiel, H.-D. (1976). Ist der Polychaet Ophryotrocha labronica ein proterandrischer hermaphrodit? Marine Biology, 38(2), 169-178.

Pfannenstiel, H.-D. (1977). Experimental analysis of the "Paarkultureffekt" in the protandric polychaete, Ophryotrocha puerilis Clap. Mecz. Journal of Experimental Marine Biology and Ecology, 28(1), 31-40.

Pfannenstiel, H.-D., \& Grünig, C. (1982). Yolk formation in an annelid (Ophryotrocha puerilis, polychaeta). Tissue and Cell, 14(4), 669-680.

Prevedelli, D., \& Simonini, R. (2001). Effects of diet and laboratory rearing on demography of Dinophilus gyrociliatus (Polychaeta: Dinophilidae). Marine Biology, 139(5), 929-935.

Prevedelli, D., \& Vandini, R. Z. (1998). Effect of diet on reproductive characteristics of Ophryotrocha labronica (Polychaeta: Dorvilleidae). Marine Biology, 132(1), 163-170.

Quinn, G. P., \& Keough, M. J. (2002). Experimental design and data analysis for biologists: Cambridge University Press.

Renner, S. S., \& Ricklefs, R. E. (1995). Dioecy and its correlates in the flowering plants. American Journal of Botany(5), 596-606.

Robotti, C., Ramella, L., Cervella, P., \& Sella, G. (1991). Chromosome analysis of 9 species of Ophryotrocha (Polychaeta, Dorvilleidae). Ophelia, 625-632. 
Rolando, A. (1984). The sex induction hypothesis and reproductive behaviour in four gonochoristic species of the genus Ophryotrocha (Annelida Polychaeta). Monitore Zoologico Italiano-Italian Journal of Zoology, 18(4), 287-299.

Rolando, A., \& Giorda, R. (1982). Male intersexes in Ophryotrocha labronica La Greca \& Bacci (Annelida Polychaeta). Monitore Zoologico Italiano-Italian Journal of Zoology, $16(1), 67-73$.

Sarre, S. D., Georges, A., \& Quinn, A. (2004). The ends of a continuum: genetic and temperature- dependent sex determination in reptiles. Bioessays, 26(6), 639-645.

Schleicherová, D., Sella, G., Meconcelli, S., Simonini, R., Martino, M., Cervella, P., et al. (2014). Does the cost of a function affect its degree of plasticity? A test on plastic sex allocation in three closely related species of hermaphrodites. Journal of Experimental Marine Biology and Ecology, 453, 148-153.

Schärer, L. (2009). Tests of sex allocation theory in simultaneously hermaphroditic animals. Evolution, 63(6), 1377-1405.

Sella, G., \& Ramella, L. (1999). Sexual conflict and mating systems in the dorvilleid genus Ophryotrocha and the dinophilid genus Dinophilus. In Reproductive Strategies and Developmental Patterns in Annelids (pp. 203-213): Springer.

Sella, G., Redi, C., Ramella, L., Soldi, R., \& Premoli, M. (1993). Genome size and karyotype length in some interstitial polychaete species of the genus Ophryotrocha (Dorvilleidae). Genome, 36(4), 652-657.

Sella, G., \& Robotti, C. (1991). Heterozygote deficiency at the phosphoglucose isomerase locus in a tyrrhenian population of Ophryotrocha-labronica (Polychaeta, Dorvillidae). Ophelia, 641-645. 
570 Simonini, R., Massamba-N'Siala, G., Grandi, V., Prevedelli, D. 2009. Distribution of the genus Ophryotrocha (Polychaeta) in Italy: new reports and comments on the biogeography of Mediterranean species. Vie et Milieu, 59, 79-88.

Thornhill, D. J., Dahlgren, T. G., \& Halanych, K. M. (2009). Evolution and ecology of Ophryotrocha (Dorvilleidae, Eunicida). Annelids in modern biology, 242-256.

Vega- Frutis, R., Macías- Ordóñez, R., Guevara, R., \& Fromhage, L. (2014). Sex change in 
592 Figure 1 Experimental set up. Juveniles $(n=330)$ were randomly assigned to one of three 593 treatments: 1. juvenile paired with an adult female 2. juvenile paired with an adult male 3 . 594 juvenile isolated. When juveniles reached a clear sexual differentiation, a subsample of these 595 sexually mature worms were screened to verify the presence of sperm (in females) or oocytes 596 (in males). The remaining worms were used to form homosexual pairs $(\mathrm{n}=87)$ or heterosexual pairs $(n=90)$. At the end of the experiment all the worms were checked for sperm in females or oocytes in males.

Figure 2. Relative frequencies of males (including males andmales with oocytes) and females (including females

601 and females with sperm) in every of the three social environments (juvenile paired with a male, with a female or isolated). $55.9 \%$ of juveniles became males when paired together with females, while only $38.3 \%$ developed as males in pair with an adult male. In a similar way, $61.7 \%$ of juveniles developed as females when they developed together with males, while $44.1 \%$ became females in pair with females. Juveniles in isolation developed $58.8 \%$ as females and $41.2 \%$ as males.

Figure 3. Frequencies (\%) of lpseudohermaphrodites (female with sperm and male with oocytes) in $O$. labronica, O. macrovifera and $O$. robusta depending on the social environment (juveniles paired with a male, a female or isolated ).

Figure 4. Variations in the developmental time (days) to sexual maturity in O. labronica, $O$. macrovifera and $O$. robusta under the effect of the social environment (juveniles paired with a male, a female or isolated) paneled seperately for every sexual phenotype (females, males and pseudohermaphrodites). The graph shows the means $\pm \mathrm{SE}$.

Figure 5. Variations in the number of rosette glands relative to body size depending onsexual phenotypes (female, male, pseudohermaphrodite), paneled separetely for O. labronica, O. macrovifera and O. robusta. 
Table 1. Main differences in the life cycle of the three tested species (mean $\pm \mathrm{SD}$ )

\begin{tabular}{cccc} 
& $\begin{array}{c}\text { Ophryotrocha } \\
\text { labronica }\end{array}$ & $\begin{array}{c}\text { Ophryotrocha } \\
\text { robusta }\end{array}$ & $\begin{array}{c}\text { Ophryotrocha } \\
\text { macrovifera }\end{array}$ \\
\hline N. Eggs/cocoon & $116 \pm 46$ & $134 \pm 51$ & $76 \pm 33$
\end{tabular}

N. segments with setae at hatching
$2 \pm 1$
0
$2 \pm 1$

N. segments with setae at $\widehat{\partial}$ definitive upper jaw

$15 \pm 2$

$15 \pm 2$

$14 \pm 2$ appearance
N. segments with setae at $q$ Oocytes appearance
time from hatching to $\widehat{\sigma}$

$16 \pm 2$

$14 \pm 2$

$14 \pm 2$

definitive u.jaw appearance

(days)

$22 \pm 5$

$28 \pm 8$

$21 \pm 7$

time from hatching to $q$ oocytes appearance (days) 
642 Table 2. Results of the GLMM testing for the effect of species and social environment on the 643 sex ratio.

644 645

\begin{tabular}{|c|c|c|c|}
\hline Predictor & Comparisons & & $P$ \\
\hline species & & $F_{2,293}=0.76$ & 0.468 \\
\hline \multirow[t]{4}{*}{ social environment } & & $F_{2,293}=4.54$ & 0.011 \\
\hline & "J+ठ" vs "J+Q" & $t=-2.74$ & 0.006 \\
\hline & "J+ふ̋" vs "isolated $\mathrm{J} "$ & $t=-0.39$ & 0.698 \\
\hline & "J+Q" vs "isolated $\mathrm{J} "$ & $t=2.43$ & 0.016 \\
\hline Random effect & & & $P$ \\
\hline sibship & & $z=1.75$ & 0.080 \\
\hline
\end{tabular}

646

647

648 
652 Table 3. Results of the GLMMs testing a) the effect of species, social environment and

653 sexual phenotype on the developmental time to sexual maturity; b) the effect of the social

654 environment for each type of sexual phenotype $(\mathrm{J}=$ Juvenile $)$.

655

\begin{tabular}{ccc} 
a) & & $\boldsymbol{P}$ \\
\hline species & $F_{2,173}=11.79$ & $<0.001$ \\
social environment & $F_{2,173}=0.46$ & 0.630 \\
sexual phenotype & $F_{2,173}=4.61$ & 0.011 \\
social environment X sexual phenotype & $F_{2,173}=6.35$ & $<0.001$ \\
\hline Random effect & & $\boldsymbol{P}$ \\
\hline sibship & $z=2.63$ & 0.008
\end{tabular}

\begin{tabular}{|c|c|c|c|c|}
\hline b) & Predictor & Comparisons & & $P$ \\
\hline \multirow[t]{4}{*}{ Females } & social environment & & $F_{2,43}=3.75$ & 0.032 \\
\hline & & "J+ठ" vs "J+Q⿱艹 & $t=2.74$ & 0.009 \\
\hline & & "J+ठ" vs "isolated $\mathrm{J} "$ & $t=1.27$ & 0.210 \\
\hline & & "J+q" vs "isolated J" & $t=-1.69$ & 0.098 \\
\hline \multirow[t]{4}{*}{ Males } & social environment & & $F_{2,79}=9.26$ & $<0.001$ \\
\hline & & "J+ठ" vs "J+Q⿱日一 & $t=3.79$ & $<0.001$ \\
\hline & & "J+ठ̂" vs "isolated $\mathrm{J} "$ & $t=-3.54$ & 0.001 \\
\hline & & "J+Q" vs "isolated J" & $t=-0.32$ & 0.754 \\
\hline Pseudoherm. & social environment & & $F_{2,47}=1.64$ & 0.206 \\
\hline
\end{tabular}

